\title{
Supplementing Effect of Abiotic Elicitor on Picroside II Content on In vitro Culture of Picrorhiza kurroa Royle ex Benth
}

\author{
Kannojia G*, Helena DS, Kumari A and Gaur AK \\ Department of Molecular Biology and Genetic Engineering (MBGE), College of Basic \\ Sciences and Humanities (CBSH), G.B. Pant University of Agriculture and Technology, \\ India
}

*Corresponding author: Kannojia G, Department of Molecular Biology and Genetic Engineering (MBGE), College of Basic Sciences and Humanities (CBSH), G.B. Pant University of Agriculture and Technology, India, Tel: +919897963447; E-mail: k.geetanjali6@gmail.com

\section{Research Article}

Volume 2 Issue 1

Received Date: July 10, 2017

Published Date: August 30, 2018

DOI: $10.23880 /$ ggtij-16000110

\begin{abstract}
In present study, copper sulphate and silver nitrate were used as elicitors to improve the productivity of useful metabolite, picroside for achieving high concentration in Picrorhiza kurroa Royle ex Benth in suspension culture. When the leaves of Picrorhiza kurroa were treated with $2 \mu \mathrm{M}, 4 \mu \mathrm{M}$ concentration of silver nitrate as elicitor, the picroside II content was enhanced in all different hours treatment .The maximum increment in the total picroside content was observed when treated with $4 \mu \mathrm{M}$ concentration of silver nitrate at $72 \mathrm{~h}\left(0.049 \mathrm{mg} \mathrm{mL}^{-1}\right)$ as compared to untreated sample. With respect to copper sulphate as elicitor, the best elicitation effect was recorded for the highest copper sulphate concentration $(40 \mu \mathrm{M})$ for all tested time intervals $(24,48$ and 72 hours respectively). For the highest concentration, copper sulphate accumulated the greatest picroside content after $24 \mathrm{~h}$ elicitation $\left(0.046 \mathrm{mg}^{-1}\right) \mathrm{mhen}^{-}$ compared with the control, from $0.046 \mathrm{~mL}^{-1}$ to $0.092 \mathrm{~mL}^{-1}$. After 24 hours, the picroside II content decreased for both elicitor concentrations, 20 and $40 \mu \mathrm{M}$ respectively. Comparison in the effectiveness of abiotic elicitors that have been used in this research, silver nitrate is the best abiotic elicitor when compared to copper sulphate.
\end{abstract}

Keywords: Elicitor; Picroside; Metabolite; Picrorhiza kurroa

\section{Introduction}

Plant cell culture is often an effective system to study the biological significance of bioactive metabolites under in vitro conditions, as well as for producing natural products for bio processing applications [1]. It has been industrially used for the synthesis of secondary metabolites [2]. The regular increase in demand in world market for natural, renewable products has refocused attention on in vitro plant materials as potential factories for secondary phytochemical products, and has paved the way for new research exploring secondary product expression in vitro [3]. Plants express a number of morphological and physiological responses to a range of physical and chemical factors from the environment, known as elicitors, which activate chemical defences in plants. The synthesis of plant secondary metabolites can be stimulated by acting on different parameters: environmental factors, use of precursors of the targeted molecules, use of elicitors and, genetic transformation of 


\section{Genomics \& Gene Therapy International Journal}

the plant [4]. Secondary metabolites production in entire plants depends on endogenous [5] and exogenous factors [6]. Enhancement of secondary metabolites by elicitor application is one of the few strategies which have recently found commercial application. Elicitors can be abiotic or biotic compounds of mainly microbial origin or non-biological origin, which upon contact with higher plant cells; trigger the increased production of pigments, flavours, phytoalexins and other defense related compounds [7]. The recent development of elicitation has opened a new avenue for the production of secondary compounds. Secondary metabolite synthesis and accumulation in cell cultures can be triggered by the application of elicitors to the culture medium [8]. Picrorhiza kurroa Royle ex Benth is an important herb in the Ayurvedic System, belongs to Family Scrophulariaceae. The plant is a representative endemic, medicinal herb, widely distributed throughout the higher altitudes of alpine Himalayas from west to east, between 3000 to $4500 \mathrm{~m}$ above mean sea level (amsl).

The medicinal importance of P. kurroa is due to its pharmacological properties like antioxidant (particularly in liver) Ansari, et al. 1988 [9], hepatoprotective Chander, et al. 1992 [10], antiallergic and antiasthamatic Dorch, et al. 1991 [11], anticancerous activity particularly in liver Joy, et al. 2000 [12] and immunomodulatory activity [13]. A hepatoprotective drug formulation, Picroliv has also been prepared from the extracts of P. kurroa $[14,15]$. The active constituents are responsible for various bioactivities obtained from the root and rhizomes. The active constituents include hepatoprotective picrosides; picroside-I and picroside-II and other metabolites like picroside-III, picroside-IV, apocynin, androsin, catechol, kutkoside, etc. [16]. Natural reserves of this plant are declining especially due to over exploitation from the wild after reports of the therapeutic properties of its glycosides. Therefore there is an urgent need for its conservation and multiplication. In vitro methods can be fine-tuned to prepare a protocol that will be commercially feasible with options for enhanced metabolite production. Present study was conducted to examine the effect of elicitors to analyze the effect of copper sulphate and silver nitrate, as abiotic elicitors on the production of picroside II in MS liquid medium cultures.

\section{Materials and Methods}

\section{Plant material}

The plants of Picrorhiza kurroa Royal ex Benth were collected from Garhwal region of Uttarakhand. These plants were established in controlled environment containment facility (250C, $65.0 \% \mathrm{RH}$ ) at College of Basic Sciences and Humanities, GBPUA\&T, Pantnagar in the same duration which was then subsequently established in vitro.

\section{Establishment of In Vitro Shoot Cultures}

In vitro shoot cultures were established from sliced shoots of subcultured plants. Initially these were cultured on MS solid medium supplemented with KIN $1.5 \mathrm{mg} \mathrm{L}$ $1+\mathrm{IAA} 1.00 \mathrm{mg} \mathrm{L}-1+\mathrm{GA} 30.5 \mathrm{mg} \mathrm{L}-1$ for 30 days. Then leaves were sliced from the shoots and were transferred into MS liquid medium containing $25 \mathrm{~mL}$ medium with same combination of phytohormone. These liquid cultures were maintained in orbital shaker at $25^{\circ} \mathrm{C}$ and $120 \mathrm{rpm}$. The insoluble PVP (0.1\%) was added for avoiding phenolics in liquid medium. After 15 days of acclimatization of leaves in MS liquid medium, elicitors treatments were given to the cultures in strictly aseptic conditions in the laminar air flow.

\section{Standard Preparation}

A stock solution of $1 \mathrm{mg} / \mathrm{mL}$ Picroside II was prepared by dissolving $1.0 \mathrm{mg}(0.001 \mathrm{~g})$ standard picroside in $1 \mathrm{~mL}$ methanol (HPLC grade).

\section{Preparation of Metabolic Elicitors}

Silver nitrate and Copper sulphate were used as abiotic elicitors. Stock solution of elicitors was prepared in distilled water and sterilized by filtration $(0.22 \mu \mathrm{m}$ syringe filter) before adding in the medium. The stock concentrations of Silver nitrate and Copper sulphate were $1 \mathrm{mM}$ and $100 \mathrm{mM}$ respectively. Elicitors treatments were applied to the in vitro liquid leaves cultures on day 15 post inoculation at concentration Silver nitrate $(2 \mu \mathrm{M}, 4$ $\mu \mathrm{M})$ and Copper sulphate $(10 \mu \mathrm{M}, 20 \mu \mathrm{M})$. The leaves samples were harvested at $24 \mathrm{~h}, 48 \mathrm{~h}$ and $72 \mathrm{~h}$ from the culture medium by filtration and frozen immediately in liquid nitrogen and stored at $-80{ }^{\circ} \mathrm{C}$ until further use. All the treatments were carried out in triplicate and results were presented by the mean of standard error $( \pm$ S.E.).

\section{Extraction}

Picrosides were extracted essentially as described by [17]. Plant leave tissues were harvested and immediately frozen in liquid nitrogen and stored in liquid nitrogen and stored at $-80^{\circ} \mathrm{C}$ till further use. The frozen samples $(100$ $\mathrm{mg}$ ) were ground to fine powder in liquid nitrogen using pestle and mortar followed by addition of $1 \mathrm{ml}$ of $80 \%$ HPLC (High performance liquid chromatography) grade methanol (Merck, Germany) with intermittent grinding 


\section{Genomics \& Gene Therapy International Journal}

for $1 \mathrm{~min}$. Extract was transferred to centrifuge tube and pestle and mortar was rinsed with $1 \mathrm{ml}$ of $80 \%$ methanol to recover the left over sample. Extracts were pooled, centrifuged at $10,000 \mathrm{~g}$ for $20 \mathrm{~min}$. and the supernatant was used for picroside-II estimation.

\section{Metabolic Profiling of Picroside II}

All the samples were filtered through $0.22 \mu \mathrm{m}$ filter before injecting in HPLC (Millipore USA) for HPLC analysis [18]. The chromatographic separation was carried out on an Agilent controller HPLC system using reverse phase non polar $\mathrm{C}-18$ column eluted in an isocratic mode with a mixture of $0.05 \%$ trifluroacetic acid and methanol: acetonitrile (1:1) in 70:30 respectively. The column elutes were monitored using PDA (Photodiode Array) detector. Isocratic elution was carried out at a flow rate of $1.0 \mathrm{~mL} / \mathrm{min}$ with injection volume of $20 \mu \mathrm{l}$ Picrosides were monitored at $264 \mathrm{~nm}$. Mobile phase was also filtered through $0.45 \mu \mathrm{m}$ membrane using filtration assembly connected with vacuum pump. The mobile phase was degassed properly before applying it on HPLC to avoid air bubble. The identification of picroside was based on the retention time and comparison of the authentic standard purchased from Life Tech. Quantification analysis was repeated for three replicates each and the means and standard deviations were calculated.

\section{Statistical Analysis of Data}

In metabolic profiling of picroside II using elicitors in HPLC experiments, data are expressed as an average of at least three separate experiments. The error bars in the charts indicates the standard deviation (S.D.) from the mean of each replicate treatment. Mean values of various treatments were subjected to one way Analysis of Variance (ANNOVA) $(\mathrm{p}<0.05)$. Experiments were performed in replicates.

\section{Result and Discussion}

Picroside II is an iridoid glycoside belonging to monoterpene class of terpenoids produced by Picrorhiza kurroa Royle ex Benth. Li et al. (2007) [19] confirmed that picroside II had an antioxidant effect and could reduce the H202-induced injury in PC12 cells to improve the cell survival and, therefore, makes this compound a highly valued secondary metabolite.

\section{Effect of Silver Nitrate Elicitation on Picroside II Production}

The effect of abiotic elicitor $\left(\mathrm{AgNO}_{3}\right)$ has been described by Tumova and Polivkova (2006) [20] reported on the production of flavonoids in the callus culture Ononis arvensis $\mathrm{L}$. The use of this abiotic elicitor proved to be good to increase the production of flavonoids in in vitro culture. The maximal production was achieved after a 24-hour elicitation with $\mathrm{AgNO}_{3}$ in a concentration $(0.5$ $\mathrm{mg} / \mathrm{L}$ ) an increase by $934 \%$ versus the control (without the elicitor's action). Zhou, et al. (2010) [21] also reported the effects of biotic and abiotic elicitors on the production of diterpenoid tanshinones in Salvia miltiorrhiza cell culture. Ag (silver nitrate) was most effective to stimulate the tanshinone production, increasing the total tanshinone content of cell by more than ten-fold $(2.3 \mathrm{mg}$ $\mathrm{g}^{-1}$ versus $0.2 \mathrm{mg} \mathrm{g}^{-1}$ in control). The results suggest that the elicitor-stimulated tanshinone accumulation was a stress response of the cell. Silybum marianum hairy root cultures treated with $2 \mathrm{mM} \mathrm{Ag}+$ showed enhanced silymarin content (by up to 2 times) compared to nontreated hairy root cultures [22]. The effect of silver nitrate elicitation was analyzed on different time interval and concentration on metabolite concentration. The picroside content was enhanced in all different hours treatment as compared to control when treated with $2 \mu \mathrm{M}, 4 \mu \mathrm{M}$ concentration of silver nitrate elicitor. The maximum increment in the total picroside II content was observed when treated with $4 \mu \mathrm{M}$ concentration at $72 \mathrm{~h}(0.049 \mathrm{mg}$ $\mathrm{ml}^{-1}$ ) as compared to untreated sample.

\begin{tabular}{|c|c|c|c|}
\hline \multirow{2}{*}{ Concentration of Silver nitrate $(\boldsymbol{\mu M})$} & \multicolumn{3}{|c|}{ Production of picroside $\mathbf{~ m g ~ m l}^{\mathbf{- 1}} \mathbf{( W / V )}$} \\
\cline { 2 - 4 } & $\mathbf{2 4} \mathbf{h}$ & $\mathbf{4 8} \mathbf{~ h}$ & $\mathbf{7 2 ~ h}$ \\
\hline Control(un-treated) & $0.046 \pm 0.06$ & $0.047 \pm 0.20$ & $0.048 \pm 0.13$ \\
\hline $2 \mu \mathrm{M}$ & $0.053 \pm 1.14$ & $0.069 \pm 0.22$ & $0.072 \pm 1.14$ \\
\hline $4 \mu \mathrm{M}$ & $0.080 \pm 0.34$ & $0.105 \pm 1.13$ & $0.129 \pm 0.42$ \\
\hline
\end{tabular}

Table 1: Influence of silver nitrate as elicitor for enhancing the production of picroside-II in in vitro dedifferentiated leaves in MS liquid medium at different time intervals.

Values are mean $\pm \mathrm{SE}$ of three replicates per treatment 


\section{Genomics \& Gene Therapy International Journal}

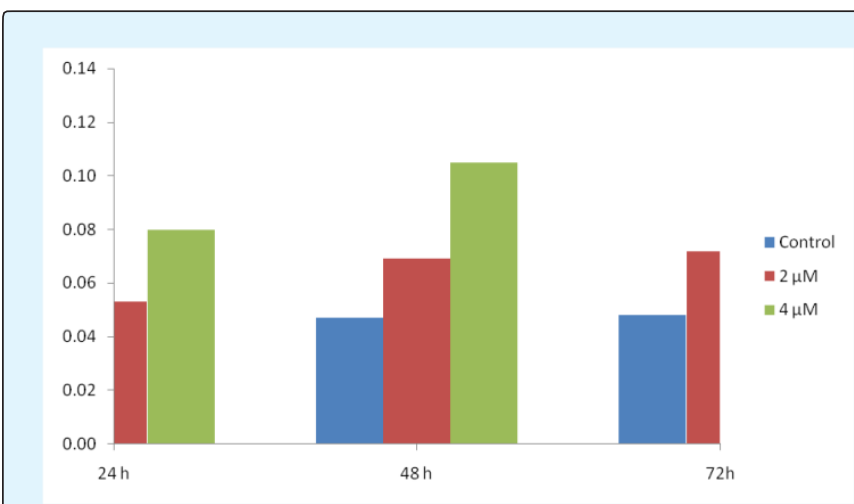

Figure 1: Influence of silver nitrate as elicitor for enhancing the production of picroside-II in in vitro dedifferentiated leaves in MS liquid medium at different time intervals.

\section{Effect of copper sulphate elicitation on Picroside II production}

Ahmed and Abd (2012) [23] reported the influence of certain abiotic elicitors on the accumulation of anthraquinones in cell suspension cultures of Rubia tinctorum L. The cultured cells were exposed to different abiotic elicitors in order to increase their productivity. Anthraquinones were quantitatively determined by HPLC analysis. The quantity of total anthraquinones was estimated on the bases of their area with respective to the area of alizarin $(0.3 \mu \mathrm{g})$ as external standard. Single treatment of $100 \mu \mathrm{M}$ methyl jasmonate, $40 \mu \mathrm{M}$ copper sulfate and $20 \mu \mathrm{M}$ salicylic acid to cell cultures of Rubia tinctorum ( 5 days old) for 48 hours enhanced the total anthraquinones accumulation to $89.45,73.55,57.86 \mathrm{mg} / \mathrm{g}$ fresh weight respectively compared to control. As per reports of Bota and Deliu (2011) [24], the effect of copper sulphate on the production of flavonoids in cell cultures of Digitalis lanata, flavonoid production was induced for line 11 after 24 hour elicitation (over 10 times more compared with the control, from $0.624 \mathrm{mg} / \mathrm{g}$ dry weight (d.w.) to $6 \mathrm{mg} / \mathrm{g}$ d.w.), for the highest elicitor concentration $(40 \mu \mathrm{M})$. After 24 hours, the flavonoids content decreased for both elicitor concentrations, 20 and $40 \mu \mathrm{M}$ respectively. With respect to copper sulphate as elicitor in Picrorhiza kurroa Royle ex Benth, the best elicitation effect was recorded for the highest copper concentration $(40 \mu \mathrm{M})$ for all tested time intervals $(24,48$ and 72 hours respectively) (Table 2, Figure 2). For the highest concentration, copper sulphate accumulated the greatest picroside II content after $24 \mathrm{hr}$ elicitation $(0.046$ $\mathrm{mg} \mathrm{ml}^{-1}$ ) when compared with the control, from $0.046 \mathrm{~mL}^{-}$ ${ }^{1}$ to $0.092 \mathrm{~mL}^{-1}$. After 24 hours, the picroside II content decreased for both elicitor concentrations, 20 and $40 \mu \mathrm{M}$ respectively. Therefore, the best elicitation was observed on $24 \mathrm{hr}$ time interval.

\begin{tabular}{|c|c|c|c|}
\hline \multirow{2}{*}{ Concentration of Copper sulphate $(\boldsymbol{\mu M})$} & \multicolumn{3}{|c|}{ Production of picroside $\left.\mathbf{~ m g ~} \mathbf{~ m l}^{-1} \mathbf{~} \mathbf{W} / \mathbf{V}\right)$} \\
\cline { 2 - 4 } & $\mathbf{2 4} \mathbf{~ h}$ & $\mathbf{4 8 ~}$ & $\mathbf{7 2} \mathbf{~ h}$ \\
\hline control(non- treated) & $0.046 \pm 0.88$ & $0.047 \pm 0.82$ & $0.048 \pm 0.61$ \\
\hline $20 \mu \mathrm{M}$ & $0.086 \pm 0.83$ & $0.052 \pm 0.55$ & $0.058 \pm 0.62$ \\
\hline $40 \mu \mathrm{M}$ & $0.092 \pm 0.70$ & $0.069 \pm 0.62$ & $0.072 \pm 1.14$ \\
\hline
\end{tabular}

Table 2: Effect of Copper sulphate as elicitor for enhancing the production of picroside-II in in vitro dedifferentiated leaves in MS liquid medium at different time intervals.

Values are mean $\pm \mathrm{SE}$ of three replicates per treatment

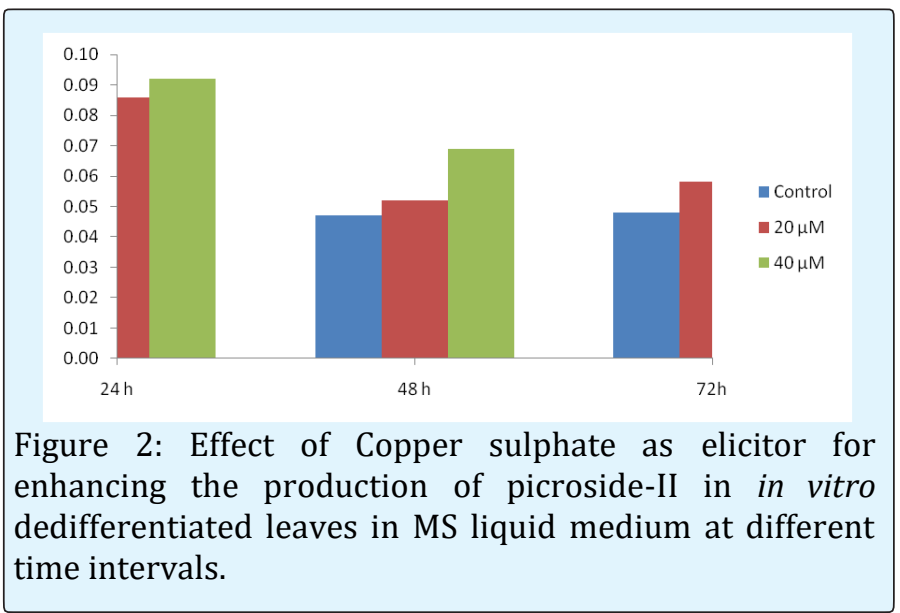

\section{Conclusions}

The results obtained prove that copper sulphate and silver nitrate are suitable to be used as elicitor in Picrorhiza kurroa liquid MS medium cultures, the same as in other plants suspension cultures, to stimulate the secondary metabolites production. On the other hand although, elicitation enhances secondary metabolism in plants or plant cells in vitro but the exact mechanism of elicitation is not exactly understood. This provides an opportunity for intensive research in the field of biosciences for exploitation of plant cells for the production of secondary metabolites. The results from this study in the $P$. kurroa leaves cultures might be effective systems for picroside II production, provided 


\section{Genomics \& Gene Therapy International Journal}

with the elicitors. As most of the elicitor chemicals are commercially available or can be readily prepared in the laboratory and easily administered to the tissues and root cultures, they are suitable for practical applications in the laboratory or large-scale production.

\section{References}

1. Walker TS, Bais HP, Vivanco JM (2002) Jasmonic AcidInduced Hypericin Production in Cell Suspension Cultures of Hypericum perforatum L. (St. John's Wort). Phytochemistry 60(3): 289-293.

2. Riedel H, Akumo DN, Thaw Saw NMM, Kütük O, Neubauer P, et al. (2012). Elicitation and Precursor Feeding Influence Phenolic Acids Composition in Vitis vinifera Suspension Culture. African Journal of Biotechnology 11(12): 3000-3008.

3. Anand S (2010) Various Approaches for Secondary Metabolite Production through Plant Tissue Culture. Pharmacia 1(1): 1-7.

4. Vu TD, Tran TLM, Biteau F, Mignard B, Fèvre JP, et al. (2006) Improvement of Secondary Metabolites Production in Hydroponic Cultures by Mechanical and Biological Processes.

5. Hashimoto T, Hayash A, Amano Y, Kohno J, Iwanari H, et al. (1991) Hyoscyamine 6-Beta-Hydroxylase, an Enzyme Involved in Tropane Alkaloid Biosynthesis, is localized at the Pericycle of the Root. J Biol Chem 266(7): 4648-4653.

6. Boitel-Conti M, Laberche JC, Lanoue A, Ducrocq C, Sangwan-Norreel BS (2000) Influence of Feeding Precursors on Tropane Alkaloid Production during an Abiotic Stress in Datura innoxia Transformed Roots. Plant Cell Tissue and Organ Culture 60(2): 131-137.

7. Pirian K, Piri K (2012) Effect of Methyl Jasmonate and Salicylic Acid on Noradrenalin Accumulation in Hairy Roots of Portulaca oleracea L. International Research Journal of Applied and Basic Sciences 3 (1): 213-218.

8. Subathra DC, Mohana SV (2011) In Vitro Studies on Stimulation of Gymnemic Acid Production Using Fungal Elicitor in Suspension and Bioreactor Based Cell Cultures of Gymnema sylvestre R.Br. Recent Research in Science and Technology 3(4): 101-104.

9. Ansari RA, Aswal BS, Chander R (1988) Hepatoprotective activity of kutkin ,the iridoid glycoside mixture of Picrorhiza kurrooa. Indian J Med Res 87: 401-404.

10. Chander R, Kapoor NK, Dhawan BN (1992) Picroliv, picroside-1 and kutkoside from $P$. kurroa are scavengers of superoxide anions. Biochem Pharmacol 44(1): 180-183.

11. Dorch W, Stuppner H, Wagner H (1991) Antiasthmatic effects of P. kurroa: Androsin prevents allergen and PAF induced bronchial obstruction in guinea pig. Int Arch Allergy Appl Immunol 95: 128133.

12. Joy KL, Rajeshkumar NV, Kuttan R (2000) Effect of Picrorhiza kurrooa extract on transplanted tumors and chemical carcinogenesis in mice. J Ethanopharmacol 71(1-2): 261-266.

13. Gupta A, Khajuria A, Singh J, Suri KA, Quazi GN (2006) Immunomodulatory activity of biopolymeric fraction RLJ-NE-205 from Picrorhiza kurrooa. Int Immunopharmacol 6(10): 1543-1549.

14. Ansari RA, Tripathi SC, Patnaik GK, Dhawan BN (1991) Antihepatotoxic properties of Picroliv, an active fraction from the rhizome of $P$. kurroa. J Ethnopharmacol 34(1): 61-68.

15. Dwivedi AK, Kulkarni D, Singh S (1997) Sensitive high-performance liquid chromatographic assay method for the determination of Picroside $\mathrm{I}$ in plasma. J Chromatogr B Biomed Sci Appl 698: 317320.

16. Weinges K, Kloss P, Henkels WD (1972) Natural products from medicinal plants. XVII. picroside-II, a new 6-vanilloyl-catapol from Picrorhiza kurroa Royle ex Benth. Justus Liebigs Ann Chem 759: 173-182.

17. Kawoosa $\mathrm{T}$ (2010) Light and temperature regulated terpene biosynthesis: hepatoprotective monoterpene picroside accumulation in Picrorhiza kurrooa. Funct Integr Genomics 10(3): 393-404.

18. Singh H, Gahlan P, Dutt S, Ahuja PS, Kumar S (2011) Why uproot Picrorhiza kurrooa, an endangered medicinal herb. Current science 100(7): 1055-1059.

19. Li T, Liu JW, Zhang XD, Guo MC, Ji G (2007) The neuroprotective effect of picroside II from hu-huanglian against oxidative stress. Am J Chin Med 35(4): 681-691. 


\section{Genomics \& Gene Therapy International Journal}

20. Tumova L, Polivkova D (2006) Effect of AgNO3 on the production of flavonoids by the culture of Ononis arvensis L in vitro. Ceska Slov Farm 55(4): 186-188.

21. Zhao J, Zhou L, Wu J (2010) Effects of biotic and abiotic elicitors on cell growth and tanshinone accumulation in Salvia miltiorrhiza cell cultures. Appl Microbiol Biotechnol 87(1): 137-144.

22. Ge X, Wu J (2005) Induction and potentiation of diterpenoid tashinone accumulation in Salvia miltiorrhiza hairy roots by $\beta$-aminobutyric acid. Appl Microbiol Biotechnol 68(2): 183-188.

23. Ahmed MA, Abd EM (2012) Influence of certain abiotic elicitors on production of anthraquinones in cell cultures of Rubia tinctorum. Spatula 2(2): 89-94.

24. Bota C, Deliu C (2011) The Effect of Copper Sulphate on theProduction of Flavonoids in Digitalis lanata Cell Cultures. Farmacia 59(1): 113. 